\title{
Menyimak (Kembali) Integrasi Budaya di Tanah Batak Toba
}

\author{
Sugiyarto \\ Program Studi Antropologi, Fakultas Ilmu Budaya \\ Universitas Diponegoro Semarang \\ Email: sugiayarto.efibe@gmail.com
}

\begin{abstract}
Toba Batak Land is one of the areas in North Sumatra Province that have dominant culture characterized by among others by: (1) the majority of indigenous Batak people; (2) Batak culture (Toba) becomes a reference for the behavior of the population in interacting in local public places; (3) Batak leadership is implemented based on elements of Batak culture. In the meantime, there are also ethnic groups of immigrants, Hindus and Christians. The embodiment of ethnicity of ethnic groups of migrants finally can integrate culturally because there are similarities of divine concepts such as Trimurti on Hindu teachings, Debata na tolu on the teachings of Parmalin in Batak Toba, as well as the Trinity in the teachings of Christians
\end{abstract}

Keyword: Batak Toba culture, hindu culture, christian culture

\section{Pendahuluan}

Fenomena kesukubangsaan dalam masyarakat majemuk (plural society) seperti di Indonesia merupakan spektrum budaya yang selalu mewarnai dinamika perkembangan berbagai suku bangsa di tanah air. Dalam spektrum sosio-kultural ternyata memainkan peranan penting dalam integrasi budaya di berbagai daerah asal suku bangsa seperti di Tapanuli, wilayah suku Batak Toba.

Pertemuan dan komunikasi antara budaya asli dengan budaya suku pendatang dapat menumbuhkan suasana yang kondusif, untuk memunculkan interaksi antarsistem budaya dan sistem sosial penduduk setempat. Perbedaan atau bahkan kemiripan konsep ketuhanan dan kosmos dapat memberikan kontribusi besar bagi mobilitas pendukung nilai budaya. Gejala inilah yang pada akhirnya memunculkan istilah integrasi, suatu proses menuju terbentuknya suatu kesatuan dengan mengkombinasikan berbagai unsur yang terpisah ke dalam suatu keseluruhan yang integral (J.A Simpson \& E.S.C Weiner, 1989 : 1065).

Integrasi antarbudaya merupakan fenomena sosial budaya yang sering menucul ke permukaan dalam multietnik di Indonesa. Di sana sebagian dari unsur kebudayaan tradisional berusaha bertahan dan hidup dalam lingkup kebudayaan baru. Pada akhirnya lahirlah proses interaksi yang saling mempengaruhi sehingga memunculkan suatu model wujud kebudayaan baru. Menurut Koentjaraningrat, ditinjau dari dimensi wujudnya, sebuah kebudayaan memunyai tiga simbol. Pertama, simbol-simbol wujud konsep atau pikiran manusia. Kedua, wujud simbol kompleks aktivitas manusia. Ketiga, wujud 
Endogami: Jurnal Ilmiah Kajian Antropologi

E-ISSN : 2599-1078

peralatan yang digunakan manusia untuk menunjang pemenuhan kebutuhan-kebutuhan manusia (Koentjaraningrat, dalam Alfian, 1985 : 99).

\section{Identifikasi Budaya Batak Toba}

\section{1. Lokasi Geografi}

Suku Batak adalah penduduk asli di propinsi Sumatra Utara. Dari perbedaan dialek yang dipergunakan dalam kehidupan dan pergaulan sehari-hari, orang Batak secara khusus terdiri dari enam sub suku, yaitu Karo, Simalungun, Pakpak, Toba, Angkola, dan Mandailing. Setiap sub suku Batak memiliki batas-batas wilayah kebudayaan yang jelas. Pada tahun 1961 orang Karo mendiami suatu wilayah paling utara di Sumatra Utara yang wilayahnya meliputi daerah induk dataran tinggi Karo, Langkat Hulu, Deli Hulu, Serdang Hulu, dan sebagian kabupaten Dairi. Di sebelah selatan dan tenggara wilayah orang Karo didiami oleh Batak Simalungun yang menempati daerah induk Simalungun. Sedangkan di sebelah barat orang Karo didiami suku Batak Pakpak menempati daerah induk Dairi Di bagian wilayah paling selatan dari propinsi Sumatra Utara merupakan lokasi orag Batak Angkola dan Mandailing. Orang Angkola mendiami daerah induk Angkola dan Sipirok, sedangkan suku Mandailing mendiami daerah induk Mandailing, Ulu, Pakatan, dan bagian selatan Padanglawas. Sementara itu, wilayah orang Batak Toba paling luas meliputi kawasan tepi danau Toba, pulau Samosir, dataran tinggi Toba, daerah Asahan Silindung, daerah antara Barus dan Sibolga (Bagun, 1982 : 95). Sejak tahun 1979 dengan diberlakukannya UU No.5 tahun 1979, wilayah orang Batak Toba berada dalam kabupaten Tapanuli Utara, kabupaten Deli Serdang, dan kabupaten Asahan.

Kabupaten Tapanuli Utara pada zaman kolonial Belanda termasuk ke dalam Karesiden Tapanuli. Di bagian selatan wilayahnya berbatasan dengan kabupaten Tapanuli Selatan, sebelah timur berbatasan dengan kabupaten Tapanuli Tengah dan kabupaten Dairi, bagian utara berbatasan dengan kabupaten Karo dan kabupaten Simalungun, dan di bagian barat wilayahnya berbatasan dengan kabupaten Asahan dan kabupaten Labuhan Batu. Sementara itu kabupaten Serdang merupakan daerag yang kaya akan hasil perkebunan karet sejak zaman Belanda. Daerah Deli Serdang tanahnya subur dan letaknya sangat strategis serta berbatasan dengan selat Malaka. Adapun kabupaten Asahan tergolong wilayah yang kaya dengan perkebunan sawit milik negara sejak zaman Belanda.

Menurut tarombo (dongeng-dongeng suci yang masih berkembang di daerah Batak) menceritakan bahwa orang Batak Toba merupakan sumber dan asal-usul semua sub-suku Batak di Sumatra Utara. Pertimbangannya adalah semua orang Batak berasal dari satu moyang yang bernama Si Raja Batak yang pada masa purba tinggal di pulau Samosir (Simanjuntak, 2001 : 2). Dalam cerita-cerita suci dari banyak suku di dunia, nenek moyang atau leluhur suatu suku bangsa biasanya disamakan dengan dewa pembawa adat "cultural hero" (Koentjaraningrat, 1985 : 232), yang pertama-tama mengajarkan kepada manusia tentang adat istiadat yang digunakan sebagai pedoman untuk memahami dan memecahkan permasalahan-permasalahan lingkungan alamiah dan sosialnya. Apabila dianalogkan dengan Si Raja Batak sebagai nenek moyang, maka dalam budaya Batak, khususnya Batak Toba ada tiga pemikirian tardisional sosio-kultural yang dalam sejarahnya dapat menjadi dasar lahirnya pertemuan dan komunikasi 
Endogami: Jurnal Ilmiah Kajian Antropologi

E-ISSN : 2599-1078

antarbudaya, yaitu sistem kepercayaan tradisional, strata dan sistem sosial, dan sistem adat istiadat.

\section{2. Sistem Kepercayaan Tradisional}

Sistem kepercayaan yang pertamakali muncul pada orang Batak Toba adalah sitolu sada (tiga dalam satu) sebagai konsepsi ketuhanan dan kosmos dalam Parmalim, aliran kepercayaan tradisional Batak Toba (Bonus Matra, 1994). Dalam konsepsi tentang kosmos dikenal dengan istilah "banua na tolu" atau alam yang tiga", yaitu banua ginjang (dunia atas), banua tonga (alam tengah), dan banua toru (alam bawah). Secara alamiah setiap manusia akan melewati tiga tahapan alam. Sebelum lahir ke dunia nyata jiwa manusia terlebih dahulu berada di banua toru, alam bawah, rahim ibunya. Setelah batas umur tertentu dalam rahim ibunya baru dapat memasuki tahapan alam kedua, yaitu dunia fana, banua tonga. Ketika ada perpisahan antara jiwa dengan raga dalam diri manusia, maka jiwa (tondi/hosa) memasuki alam tahap akhir yang disebut banua ginjang, alam akhirat, dunia abadi.

Pemikiran tradisional tentang kosmos kemudian dikembangkan untuk mengkonsepsikan masalah ketuhanan yang dikenal dengan konsep "debata na tolu", Tuhan Nan Tiga, sebagai manifestasi Tuhan Yang Maha Esa (Mulajadi na Bolon) (Sumardjo, 2002 : 138-140) memiliki kekuasaan mencipta, menghukum, dan mengadili manusia yang telah menjalani kehidupan dalam kosepsi banua na tolu. Sebagai pencipta, pemberi berkah, dan pemberi keadilan di hari kiamat, disebut Batara Guru/Tuan Batara Guru/Mulajadi na Bolon yang mengusai alam atau dunia atas. Penguasa dunia tengah adalah Batara Sori/patuan Harajaon Sori/Silaon na Bolon yang bertugas memberikan kutukan kepada manusia yang berdosa. Dan penguasa dunia/alam bawah adalah Patuan Bala Bulan/Bela Bulan/ Pane na Bolon bertugas mengusai makhluk halus dan dunia pedukuna (Bangun, 1982 :113-114; Bonus Matra 1994 : 4; Simanjuntak, 2001 : 164-165).

Dalam kepercayaan tradisional Batak Toba yang menonjol lainnya adalah konsepsi tentang jiwa (tondi/hosa). Jiwa dipercayai memiliki kekuatan yang luar biasa, ketika jiwa masih bersatu dengan raga ditandai adanya kehidupan, tetapi sewaktu jiwa melepaskan diri dengan raga yang terjadi adalah kematian. Oleh karena itu dikonsepsikan bahwa setiap manusia harus dilekati oleh tiga unsur dalam dirinya, yaitu tondi/hosa (nyawa), mudar (darah), dan sibuk (urat/daging). Apabila salah satu unsur lepas berarti tidak ada keseimbangan dalam diri manusia, sehingga yang ada kematian. Dalam konsep kekuatan jiwa dalam budaya Batak Toba ternyata sejalan dengan teori jiwa dari E.B Tylor, antropolog Inggris dalam bukunya yang berjudul Primitive Cultures.tahun 1873 (Koentjaraningrat, $1985: 221-222$ ).

\section{3. Strata dan Sistem Sosial}

Orang Batak Toba sebagai salah satu sub-suku Batak, memiliki perangkat struktur dan sistem sosial warisan dari nenek moyang. Struktur dan sistem sosial berfungsi mengatur dan mengendalikan tata hubungan sesame anggota masyarakat, baik yang menjadi kerabat dekat, kerabat, luas, saudara satu marga (dongan sabutuha/dongan tubu) maupun masyarakat umum. Struktur sosial yang dimiliki oleh Batak Toba pada hakekatnya berdasarkan system sosial marga. Dari garis keturuan bapak (patrilineal),

Sugiyarto 
mereka mempunyai salah satu unsur struktur sosial yang disebut dongan sabutuha atau dongan tubu.

Berdasarkan sistem perkawinan, sumber dari pihak istri menjadi unsur kedua dalam struktur sosial yang dinamakan hulahula. Sementara itu, kelompok sosial pengambil istri menjadi unsur sosial ketiga yang diberi julukan kerabat boru. Dengan demikian dalam struktur sosial orang Batak Toba terdapat tiga unsur dalam sistem sosial yang didasarkan pada garis keturunan dan sistem perkawinan. Ketiga unsur strata dalam sistem sosial yang demikian itu disebut dalihan na tolu. Ketiga unsurnya saling terikat dan saling membutuhkan. Pada dasarnya ketiga unsur dalam dalihan na tolu tidak pernah ada yang saling melebihi.

Dalam kehidupan sehari-hari keberadaan ketiga unsur dalam sistem sosial itu ternyata diperkokoh dengan sistem kepercayaan budaya Batak Toba, sehingga kedudukan hulahula lebih tinggi dan lebih istimewa. Simbol tingginya kedudukan sosial pihak hulahula dipandang sebagai sumber restu yang bernilai kepercayaan. Oleh karena itu, dalam kosep kemasyakatan dalihan na tolu diperintah atau disuruh apalagi dipaksa oleh pihak boru. Hal ini diperkuat dengan pepatah adat Batak Toba yang berbunyi somba mar hulahula (sembah sujud kepada pihak istri). Sembah sujud dalam konteks tingkah laku, sikap pandang, pemberian, pelayanan sosial dan pelayanan adat (Simanjuntak, 2001: 122).

Unsur sosial selanjutnya adalah kerabat dongan sabutuha atau dongan tubu, yaitu saudara semarga atau saudara satu perut ibu, satu darah dari garis keturunan bapak. Kelompok satu marga secara adat adalah saudara dekat. Ungkapan budaya Batak Toba yang mengukuhkan hubungan bersaudara dalam dongan sabutuha berbunjyi "manat mar dongan sabutuha" (hati-hati dan bijaksanalah terhadap saudara semarga). Bahkan untuk memperkokoh nilai persatuan dalam dongan sabutuha ditunjang dengan pepatah adat yang berbunyi "sisada sipanganon, sisada hailaon", artinya satu dalam makanan, satu dalam kemiskinan. Ungkapan seperti ini dapat dipandang sebagai peringatan bagi orang yang masih satu marga agar tetap waspada dan berhati-hati untuk antisipasi munculnya konflik internal dalam sat marga.

Kelompok ketiga dalam sistem kekerabatan Batak Toba adalah pihak boru (kerabat dari suami). Sebagai unsur ketiga dalam sistem sosialnya, pihak boru dapat diperintah oleh kelompok hulahula dan wajib mematuhinya. Pada setiap perhelatan atau horja yang diselenggarakan oleh pihak hulahula, maka kerabat boru adalah sebagai pihak penanggungjawab dalam pelaksanaannya (Persada Marga Harahap Dohot Anakboruna, 1993 : 24-25). Sekalipun demikian secara fungsional tugas dan tanggungjawab yang dilakukan oleh pihak boru tetap dipandang sebagai simbol kedudukan dan kehormatan yang tinggi. Bahkan sebaliknya, boru akan merasa diremehkan dan direndahkan derajatnya kalau tidak diperintah untuk melakukan fungsi sosialnya sebagai pihak lakilaki. Ada ungkapan budaya Batak Toba sebagai landasan sikap hulahula kepada boru yang berbunyi "elek marboru", membujuk boru.

Apabila sistem kepercayaan tradisional (banua na tolu dan debata na tolu) diintegrasikan dengan struktur dan sistem sosial (dalihan na tolu) dalam budaya Batak Toba, unsur sosial hulahula sejajar dengan Batara Guru serta Banua Ginjang. Sementara kelompok boru dapat diidentikkan dengan Bala Bulan yang berada dalam tahap Banua Toru. Konsep budaya Batak Toba inilah yang menjadi factor pendukung munculnya 
Endogami: Jurnal Ilmiah Kajian Antropologi

E-ISSN : 2599-1078

integrasi budaya dengan agama Hindu dengan sistem kepercayaan Trimurtinya serta konsep ketuhanan Trinitas dalam ajaran Kristen

\section{Stereotip Budaya Pendatang}

\section{1. Budaya Hindu}

Tidak dapat diketahui secara pasti sejak kapan budaya Hindu mulai berkembang di tanah Batak. Dari beberapa peninggalan tua baik berwujud candi Portibi di Padanglawas maupun tulisan Batak yang mirip dengan tulisan Hindu Jawa, menunjukkan pernah terjadi pertemuan dan komunikasi antara orang Batak dengan Hindu. Di samping itu, dengan adanya cerita-cerita mitologi tentang konsep ketuhanan, jiwa, penciptaan dunia versi Batak Toba merupakan hasil integrasi budaya Hindu dengan sistem kepercayaan tradisional Batak.

Dalam sistem kepercayaan Hindu disebut dengan "pancasraddha", yaitu lima kepercayaan terhadap Tuhan Yang Maha Esa (Shang Hyang Widhi), jiwa (atman), Karmaphala, Samsara, dan Moksa. Kepercayaan terhadap Shang Hyang Widhi disebut dengan Trimurti, yaitu Tuhan memanesfatisan diri ke dalam tiga bentuk dewa. Sebagai Brahma bertugas mencipta makro dan mikro kosmos. Segala yang telah dicipta harus dirawat, dipelihara secara arif dan bijaksana, sehingga Wisnu dianalogkan sebagai dewa pemelihara. Sementara itu Syiwa disebut sebagai dewa waktu (dewa maha kala dan dewa pengetahuan (dewa maha guru).

Sejalan dengan teori EB Tylor tentang jiwa, ajaran Hindu juga percaya bahwa atman/jiwa itu memiliki kekuatan luar biasa. Ketika jiwa bersatu dengan raga, maka ada kehidupan, tetapi sewaktu-waktu jiwa juga bisa melepaskan diri dari raga sehingga yang terjadi adalah kematian. Setelah keluar dari raga manusia, jiwa mempunyai kemampuan yang dahsyat, bisa memilih berbagai jenis wadah baru untuk kehidupan berikutnya. Konsepsi inilah yang dalam ajaran Hindu dikenal dengan istilah "reinkarnasi".

Setiap manusia di dalam pemenuhan kebutuhan-kebutuhannya terikat oleh hukum sebab-akibat. Hasil perbuatan inderawi dan akal budi manusia membawa konsekuensi baik atau buruk, pahala atau dosa, surga atau neraka. Konsepsi tentang hasil tindakan inilah dalam agama Hindu disebut karmaphala, hukum sebab-akibat perbuatan manusia secara personal. Implikasi dari karmphala kemudian diikuti oleh kepercayaan terhadap punarbhawa (samsara) dan moksa. Punarbhawa atau samsara menunjuk pada suatu proses kelahiran kembali dari jiwa atau atman yang akan dialami oleh setiap manusia tergantung dari hasil kehidupan sebelumnya. Adapun tujuan akhir dari setiap kehidupan manusia Hindu adalah moksa, bebas penderitaan yakni bersatnya jiwa yang abadi dengan Tuhan.

Dalam agama Hindu percaya bahwa akibat dari hasil kehidupan manusia selalu dihadapkan pada konspsi kosmos yang disebut kepercayaan triloka, tiga alam kehidupan jiwa. Pertama, swahloka, alam atas, yaitu tempat bersemayamnya para dewa Hindu. Swahloka dalam kepercayaan petani desa Trunyan di Bali, masyarakat tradisional yang masih melestarikan sebagian budaya asli Bali, disebut khahyangan (Danandjaya, 1980 : 345). Alam tengah atau bhuahloka adalah dunia fana, tempat orang Hindu mengamalkan ajaran dharma. Adapun tingkatan alam yang paling rendah adalah bhurloka, alam bawah, alam binatang, tempatnya manusia berbuat dosa. 
Endogami: Jurnal Ilmiah Kajian Antropologi

E-ISSN : 2599-1078

\subsection{Budaya Kristen}

Ketika Stamford Raffles menjabat Gubernur Jenderal di Jawa (1811-1816) senantiasa diselimuti kekawatiran jika muslim Aceh dan Islam Minangkabau bergabung maka akan menjadi satu kekuatan besar yang dapat mengancam kekuasaan Inggris di Sumatra. Upaya memisahkan bersatunya kedua suku bangsa Aceh dengan Minangkabau dilancarkan. Raffles segera memberikan ijin dan bahkan mendorong kaum misionaris Kristen untuk mengembangkan agama ke daerah Tapanuli, wilayah kekuasaan orang Batak Toba. Strategi pemisahan ini tentunya berdasarkan pertimbangan agar ada satu suku pemisah yang memeluk agama di luar Islam. Pilihan itu jatuh pada orang Batak (Toba) sebagai suku yang belum beragama Islam tetapi memiliki sistem kepercayaan tradisional yang esensi ajarannya ada persamaannya dengan kepercayaan Kristen tentang Tritunggal.

Untuk merealisasikan strategi itu pada tahun 1820 Baptist Mission Society di Inggris mengirimkan tiga misionarisnya yakni Richard Burton (ahli bahasa dan etnologi), Nathani Ward (ahli kesehatan), dan Evans Brookers (ahli pendidikan) ke Tapanuli. Hubungan dengan para raja dan kepala adat di kawasan Batak Toba segera dijalankan. Pada tahun 1824 penyebaran agama Kristen ditolak oleh orang Batak, sebab mereka sudah mempunyai sistem kepercayaan tradisional Parmalim dan nilai-nilai budaya yang telah berakar di kalangan orang Batak. Suku Batak Toba tidak berani meninggalkan adat dan agama nenek moyang yang dianggap sebagai pedoman dalam pergaulan dan pemenuhan kebutuhan mereke sehari-hari. Sekali pun demikian para raja dan ketua adat Batak masih memberikan kesempatan kepada kaum misionaris untuk mensosialisasikan Kristen dengan syarat misionaris dapat menghantarkan orang Batak pada pemilikan kekayaan (hamoraon), kejayaan (hagabeon), dan kekuasaan (hasangapon), demikian kata Simanjuntak $(2001 ; 112)$.

Setelah beberapa daerah di Sumatra termasuk Tapanuli dikembalikan kepada penguasa Belanda (Traktat London 1824), pemerintahan Belanda segera mengusir ketiga misionaris Inggris dari wilayah orang Batak. Pada tahun yang sama di Tapanuli terjadi perang Paderi yakni penyerbuan orang Islam Minangkabau ke kawasan orang Batak yang dipandang sebagai penghalang proses slamisasi di tanah Batak.

Pada tahun 1834, setelah perang Paderi di Tapanuli, missi Kristen Amerika dan Belanda mengutus misionaris untuk menyebarkan ajaran Kristen di kawasan suku Batak Toba. Kedua misionaris Amerika juga tidak berhasil Mereka dibunuh orang Batak, sebab warga suku Batak merasa resah dan tidak aman secara psikologis setelah perang Paderi yang dipandang disebabkan oleh kehadiran kaum misionaris Inggris sebelumnya. Orang Batak Toba mulai membenci orang Barat (etnis kulit putih) yang dipandang sebagai penyebab munculnya keresahan sosial di Batak (Simanjuntak 2001: 113).

Kehadiran Nommensen, tokoh pengembang agama Kristen Jerman, di Tapanuli pada tahun 1862 dapat membawa suasana baru bagi orang Batak. Secara perlahan tetapi pasti orang Batak diberikan kesadaran tentang sisi-sisi kemunsiaan tentang kebersihan, kesehatan, pertanian, pertukangan, dan perdamaian. Strategi pengembangan agama Kristen menggunakan metode pendekatan multisistem seperti menjalin persahabatan dengan para kepala marga, raja-raja, dan orang-orang yang mempunyai pengaruh kuta di masyarakat Batak. Menyembuhkan orang sakit, membantu ketrampilan di bidang pertanian dan pertukangan, menghormati sistem kepercayaan, mempertahankan sistem

Sugiyarto 
adat perkawinan tradisional, merupakan langkah-langkah yang pada akhirnya disambut baik oleh adat Batak. Membantu rakyat secara langsung menyebabkan orang Batak semakin dapat menempatkan agama Kristen sebagai bagian dari mereka, dan orang Barat tidak lagi dipandang sebagai orang asing yang perlu dimusuhi. Dengan metode pendekatan yang adaptatif itulah merupakan kunci keberhasilan Nommensen dalam mengkristenkan orang Batak khususnya Batak Toba dalam kurun waktu empat dasawarsa.

\section{Integrasi Budaya Tradisional dengan Budaya Pendatang}

Kepercayaan keagamaan Batak Toba asli (Parmalim) bertumpu pada kekuatan roh yang disebut tondi dan begu. Dalam ajaran Parmalim bahwa setiap manusia dalam tubuhnya selalu dilekati tiga kekuatan yang beda wujud tetapi saling mengisi dan memberi, sehingga dapat menciptakan kesatuan yang yang disebut manusia individual. Kekuatan yang tiga itu adalah jiwa (tondi atau hosa), darah (mudar), dan daging/urat (sibuk) (Matra, 1994 : 6-7). Artinya jiwa tidak akan mau bersatu dengan raga kalau di dalam tubuh manusia tidak ada darah, sebaliknya darah tidak akan berfungsi jika tidak ditunjang oleh daging atau urat sebagai sarana distribusi darah ke seluruh tubuh manusia.

Setelah jiwa meninggalkan raga maka namanya berubah dari tondi/hosa menjadi begu, yaitu tondinya orang yang meninggal dunia. Dalam kepercayaan Batak Toba, semua tingkah laku begu sama seperti tingkah laku manusia tetapi kegiatannya dilakukan pada malam hari. Di kalangan suku Batak Toba, begu yang terpenting adalah ruh nenek moyang. Kalau begu yang dulunya sebagai tondi/hosa manusia kaya, maka upacara untuk menghormatinya dilakukan secara besar-besaran. Upacaranya disertai dengan gondang (musik Batak) dan dengan sesajian yang disebut tibal-tibal (Bagun, 1982 : 114-115).

Untuk memperkuat diri melawan begu jahat diperlukan media perantara yang disebut datu (dukun). Dengan ucapan mantra, seorang dukun memperkuat diri untuk mengusir begu jahat yang sering mengganggu manusia. Oleh orang Batak Toba manteramantera mengusir ruh jahat dituliskan dalam kitab primbon Batak. Menurut Simanjuntak, primbon Batak Toba itu dipengaruhi oleh ajaran Hindu (Simanjuntak, 2001: 101).

Pada dasarnya orang Batak Toba tidak memiliki konsep yang mendasar tentang ketuhanan. Agama Hindu yang membawa konsep ketuhanan dengan nama Trimurti yang kemudia oleh orang Batak disintesekan ke dalam konsep ketuhanan budaya tradisionalnya sehingga disebut Debata na Tolu. Di sisi lain konsep tentang kosmos dalam agama Hindu dikenal Triloka, oleh orang Batak Toba diakumulasikan dalam pengertian Banua na Tolu. Adanya konsep ketuhanan dan kosmos yang berkembang di kalangan orang Batak Toba sebagai integrasi budaya lokal dengan Hindu dapat mempermudah diterimanya agama Kristen oleh orang Batak Toba pada pertengahan abad ke-19. Sementara itu, konsep kosmos Banua na Tolu dalam kebudayaan Batak Toba (banua ginjang, banua tonga, banua toru) dapat dianggap identik dengan konsep Kristen yang membagi kosmos menjadi tiga, yaitu surga, dunia, dan neraka. Persamaan konsep kosmos juga dipandang sebagai factor pendukung pengembangan ajaran Kristen di Batak Toba.

Bagi orang Batak Toba, kekuasaan adalah tujuan hidup yang teramat penting dalam kehidupan. Tondi dan begu menguasai kehidupan orang Batak Toba. Agama Hindu melegalisasi kekuasaan itu dalam kekuatan yang sifatnya perorangan yang 
Endogami: Jurnal Ilmiah Kajian Antropologi

E-ISSN : 2599-1078

dibutuhkan setiap orang Batak Toba agar dapat menguasai roh dan hantu. Oleh karena itu ajaran Hindu yang masuk wilayah Batak Toba dapat mengembangkan dan memperkuat kuasa personal. Kuasa personal inilah yang kemudian semakin berkembang dan didambakan, baik dalam kehidupan keagamaan Kristen maupun kehidupan organisasi sosial yang lebih jauh lagi dikembangkan oleh pemerintah kolonial Belanda di Batak Toba hingga kini.

\section{Simpulan}

Ada tiga dimensi baru yang menjadi landasan utama munculnya integrasi budaya di Batak Toba. Pertama, kesamaan konsep ketuhanan antara kepercayaan Hindu (Trimurti) dengan ajaran Parmalim Batak Toba (Debata na Tolu). Kedua, kemiripan pemikiran tentang kosmos Triloka dalam agama Hindu berhadapan dengan konsep alam yang tiga (Banua na Tolu) di Batak Toba. diperkenalkan oleh budaya Hindu kepada kepercayaan asli Batak Toba. Ketiga, korelasi tondi dan begu dalam sistem kepercayaan asli Batak Toba dengan kepercayaan terhadap atman - samsara pada ajaran Hindu. Dari wajah baru inilah yang kemudian berhadapan dengan agama Kristen dan kebudayaan Barat.

\section{Daftar Pustaka}

Bangun, Payung. 1982. "Kebudayaan Batak" dalam Manusia dan Kebudayaan di Indonesia (ed. Koentjaraningrat). Jakarta: Djambatan

Danandjaja, James. 1980. Kebudayaan Petani Desa Trunyan di Bali. Jakarta : Pustaka Jaya Gatra.

Koentjaraningrat. 1985. Beberapa Pokok Antropologi Sosial. Jakarta: PT Dian Rakyat

Koentjaraningrat. 1985. "Persepsi tentang Kebudayaan Nasional dalam Persepsi Masyarakat tentang Kebudayaan (ed. Alfian). Jakarta: PT Gramedia.

Parsadaan Marga Harahap Dohot Anakboru. 1993. Horja. Adat Istiadat Dalihan Na Tolu. Bandung: PT Grafiti.

Simanjuntak, Bungaran Anhonius. 2001. Konflik Status dan Kekuasaan Orang Batak Toba. Yogyakarta : Penerbit Jendela.

Simson, J.A \& E.S.C Weiner "The OxfordEnglish Dictionary", dalam Singgih Tri Sulistiyono "Beberapa Persoalan Konseptual Mengenai Integrasi Ekonomi di Indonesia", dalam Lembaran Sastra, No.23 Tahun 1997

Soekmono. 1973. Pengantar Sejarah Kebudayaan Indonesia. Jilid 2. Yogyakarta ; Kanisius

Sumardjo, Jakob. 2002. Arkeologi Budaya Indonesia. Yogyakarta : Qalam 